\title{
CARDIAC MYXOMATA AND AORTIC SADDLE EMBOLISM
}

\author{
BY \\ A. BARHAM CARTER, K. G. LOWE, AND I. G. W. HILL \\ from the Ashford Hospital, Middlesex, Arbroath Infirmary, and Department of Medicine, Queen's College, University \\ of St. Andrews \\ Received October 15, 1959
}

The exact nature of cardiac myxomata and how far it is neoplastic or thrombotic is still disputed, but their common clinical manifestations are well recognized: inconstant murmurs, cardiac embarrassment, syncope, arrhythmia, and pulmonary or systemic embolism (Goldberg and Steinberg, 1955; Paquet, 1956). Systemic emboli are said to occur, most commonly in the kidneys, brain, and extremities (Prichard, 1951) and may consist of tumour fragments or surface thrombi (Anderson and Dmytryk, 1946; Paquet, 1956). Recently Edwards and Johnson (1959) described the case of an elderly woman who developed aortic saddle embolism and had an embolectomy at which the material occluding the aorta was noted to be jelly-like. She died shortly after operation and was shown post-mortem to have had a left atrial myxoma, the histological appearances of the cardiac tumour and the embolus being identical. Brewin (1951) also reported a case of aortic saddle embolism due to a left atrial myxoma in a 42-year-old man, in whom the whole tumour broke off from its stalk-like attachment to the margin of the fossa ovalis and occluded the distal aorta: the patient died within two days and the diagnosis was made post-mortem.

We have encountered two examples of saddle embolism associated with myxomata. In one a myxoma of the right atrium resulted in hæmorrhage in the interatrial septum with thrombus formation in the left atrium and subsequent fatal embolism. In the second the embolus consisted of tumour and was presumed to have come from the left side of the heart, though this could not be proved, even by angiocardiography: the patient underwent successful embolectomy. This would appear to be the first ante-mortem diagnosis of cardiac (or at least vascular) myxoma by embolectomy, a procedure forecast by Bahnson and Newman (1953) and Paquet (1956).

\section{CASE REPORTS}

Case 1. A married woman, aged 22, was admitted to hospital as an emergency. An hour previously while out shopping she had felt a sudden pain and a click in the lower part of her back and her legs had given way beneath her. A medical student found her lying in the road unable to use her legs and arranged her admission to hospital by ambulance. Her previous health had been excellent apart from occasional migraine. She had had two normal pregnancies. Direct questioning of her husband failed to evoke any history of syncopal attacks or symptoms suggestive of pulmonary or systemic embolism.

Physical examination showed a pale, young woman, screaming, moaning, and throwing herself about, but tending to keep her knees and hips flexed. Her pulse was regular at 100 a minute, her temperature $101^{\circ} \mathrm{F}$, and her blood pressure $120 / 75$. No abnormality was noted in her head and neck, upper limbs, or chest. The abdomen was flaccid and showed striæ gravidarum. The abdominal aorta was not palpable. The vulva and vagina were violaceous. The lower limbs were cold and white below mid-thigh and all their pulses were absent. There was flaccid paralysis and complete anæsthesia below the knees.

The hæmoglobin was $13.2 \mathrm{~g}$. per $100 \mathrm{ml}$. and the white cell count 18,600 per cu. $\mathrm{mm}$. $(83 \%$ polymorphs, $15 \%$ lymphocytes, $2 \%$ eosinophils). The blood sedimentation rate was $37 \mathrm{~mm}$. an hour (Westergren). A catheter sample of urine showed no protein, sugar, or other abnormality on microscopic examination. The Wassermann test was negative. A chest X-ray showed no abnormality. On oscillometry, no deflection was detected in thighs or calves. 
The differential diagnosis at this point lay between dissecting aneurysm and saddle embolism of the aorta. Three hours after admission, when seen by Mr. N. Matheson, she was more co-operative and had more power in her thigh muscles. Mr. Matheson noted the absence of calf tenderness and the presence of intermittent intense pallor and severe pain (without swelling of the limbs), all suggesting that a spasmodic element was prominent. In view of her age and the absence of obvious arterial or cardiac disease, he advised conservative treatment.

Accordingly she was treated with heparin (intravenously) 10,000 international units ( $77 \mathrm{mg}$.) followed by 7500 units i.u. (58 mg.) 4 hourly; morphine sulphate, 0.25 grains $(15 \mathrm{mg}$.) subcutaneously; priscol $25 \mathrm{mg}$. intravenously; nicotinic acid $100 \mathrm{mg}$. intravenously; papaverine $10 \mathrm{mg}$. intramuscularly, and penicillin 500,000 units 6-hourly intramuscularly. Following this treatment vasodilation with flushing and warmth was noted in the upper half of the body and for the first time venous mottling became apparent in the legs, and there was thought to be intermittent pulsation in the femoral arteries. Attempts at femoral artery puncture were unsuccessful but local infiltration with $10 \mathrm{ml}$. of 1 per cent procaine into the region of the arteries was carried out, without obvious improvement. Further injections of priscol were given and nine hours after admission $60 \mathrm{mg}$. of procaine in $20 \mathrm{ml}$. normal saline was injected intravenously and was followed by increased mottling of the legs. During the night, 12 hours after admission, pulsation was felt in the right femoral artery and increased skin temperature as low as the knees; the calf muscles were, however, stiffening and the feet were still dead white. The next morning, 18 hours after admission, the thighs were now cold and the calves livid; paralysis and anæsthesia were complete below the waist. The blood pressure was unobtainable in the left arm and recorded as 85/50 in the right. A few ounces of urine were obtained by catheter. She was now sinking rapidly and all treatment except morphine was discontinued. She died 58 hours after admission.

Post mortem (Dr. W. F. Hamilton). The important findings were in the heart and aorta (Fig. 1). The

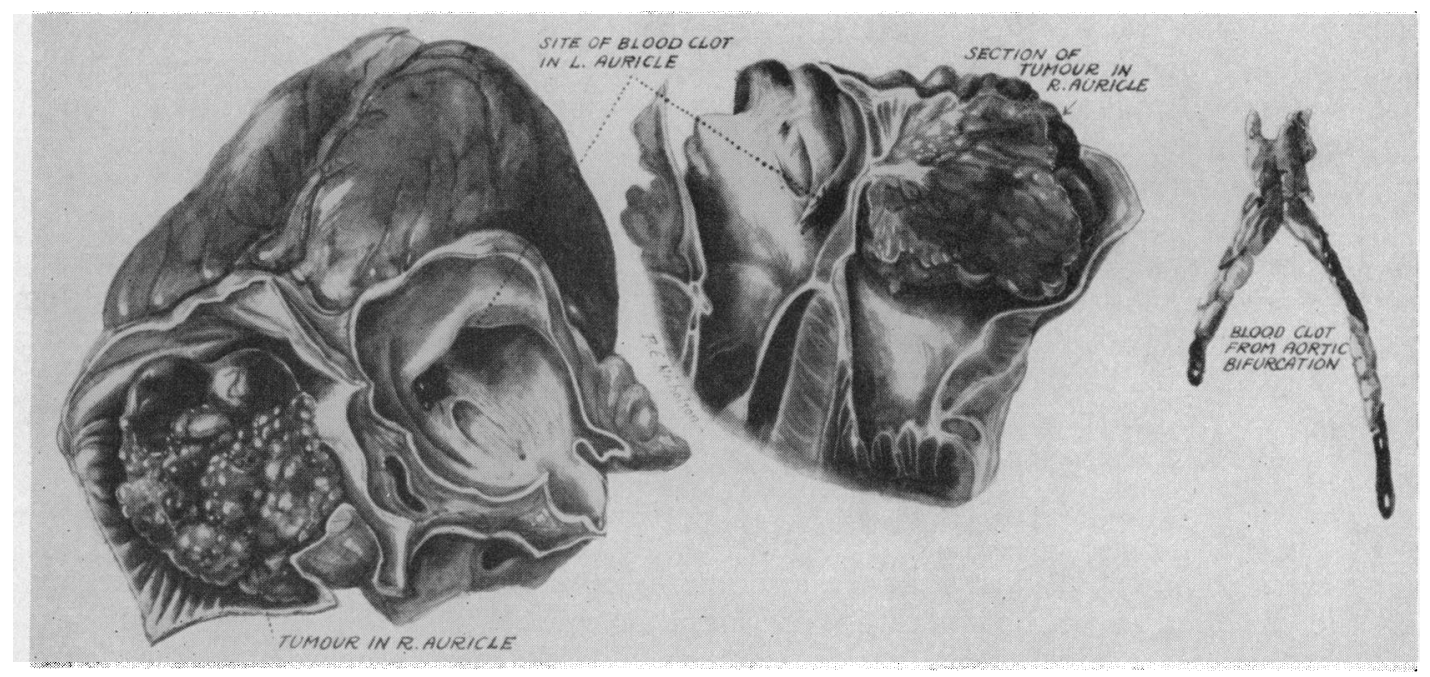

Fig. 1.-A black and white print from a colour drawing of the main necropsy findings in the heart and the saddle thrombus at the bifurcation of the aorta. Case 1.

right atrium was a little dilated, and attached to its septal wall in the region of the fossa ovalis by a pedicle, $1 \mathrm{~cm}$. long, was a tumour $(4 \times 3 \times 2.5 \mathrm{~cm}$. $)$. Its surface was lobulated and smooth and its consistency soft. Both the external and cut surfaces were mottled, dark red and yellow. The endocardium was otherwise normal and there were no ante-mortem clots. In the left atrium there was an ante-mortem clot with a ragged surface attached to the septal wall opposite the attachment of the tumour in the right atrium. There were no other abnormalities in the heart.

The aorta showed a few fatty streaks and at its bifurcation contained a Y-shaped embolus extending into the common iliac arteries (Fig. 1). The embolus was rather thin and did not fill the lumina either of the aorta or the iliac arteries. Histologically the tumour was a typical myxoma. The interatrial septum was 
intact except that on the left side there was adherent blood clot, part of which was apparently under the endocardium.

Case 2. This woman, aged 60 , was running after her grandchild at 10.30 p.m. when she suddenly lost the power of both her legs and developed severe pain in the lumbar region and in both legs. She was admitted to hospital in a state of severe clinical shock. The lower limbs were paralysed, anæsthetic, cold, and pulseless. There was no abnormality on general examination, and, in particular, no clinical evidence of heart disease nor cardiographic changes of myocardial infarction.

Aortic embolectomy was performed by Professor D. M. Douglas at 1 a.m. the next morning. The material removed at operation looked like tumour tissue rather than thrombus and was therefore sent for histological examination, which was reported as being "typical myxomatous tissue." There was a rapid clinical recovery to normal within the next four days.

During convalescence, further studies were carried out. Auscultation revealed no murmurs at any time. A chest X-ray (including cardiac screening) showed no abnormality, and the electrocardiogram showed ventricular ectopic beats, but no other abnormality. For angiocardiography, $50 \mathrm{ml} .70$ per cent pyelosil were injected into an antecubital vein and records were taken at the rate of two per second for 10 seconds on a biplane Schonander machine. The antero-posterior films jammed at $4 \frac{1}{2}$ seconds. The left atrium was clearly visualized in the lateral films at 5 seconds following the return flow of blood through the pulmonary circulation. No intra-atrial tumour mass was visualized.

Two months later, the patient was discharged fit. She had been on holiday when her illness started so she has not been closely followed up by us. However, she was seen as an outpatient eight months after operation, when her general condition and the vascular findings in the legs were satisfactory.

\section{Discussion}

These two case reports illustrate that myxomata must be borne in mind as a cause of systemic embolism and aortic bifurcation block, either by the dislodgement of tumour fragments or of related thrombi. In the first patient the right atrial myxoma led to thrombus formation in the left atrium opposite to the tumour attachment, presumably secondarily to mechanical trauma to the interatrial septum brought about by the tumour during cardiac systole. Subsequent dislodgement of a fragment of left atrial thrombus accounted for the aortic embolism.

In the second patient following successful embolectomy the embolus was proven histologically to be myxoma tissue. We can only speculate regarding its origin. Prichard (1951) states that myxomata occur almost exclusively in the atria, about three-quarters of them in the left atrium. Accordingly this patient was submitted to angiocardiography but no large interatrial mass could be demonstrated. If the left atrium was the site of the myxoma, then most of the tumour must have broken off to form the embolus as in the case reported by Brewin (1951). In view of her present state of good health, no further investigations have seemed warranted.

\section{SUMMARY}

Two cases are reported illustrating the association between myxomata and aortic bifurcation block. In one a right atrial myxoma led to left atrial thrombus formation and systemic embolism. In the other successful embolectomy was carried out and the diagnosis of myxoma was made from histological examination of the embolus.

We are indebted to Dr. W. F. Hamilton and Dr. George Smith for pathological reports and to Mr N. Matheson and Professor D. M. Douglas for their surgical managements of the patients, and to Dr. C. Pickard for the angiocardiographic interpretation.

\section{REFERENCES}

Anderson, W. A. D., and Dmytryk, E. T. (1946). Amer. J. Path., 22, 337.

Bahnson, H. T., and Newman, E. V. (1953). Bull. Johns Hopk. Hosp., 93, 150.

Brewin, T. B. (1951). Guy's Hosp. Rep., 100, 278.

Edwards, A. T., and Johnson, W. (1959). Brit. J. Surg., 46, 371.

Goldberg, H. P., and Steinberg, I. (1955). Circulation, 11, 963.

Paquet, E. (1956). Canad. med. Ass. J., 74, 121.

Prichard, R. W. (1951). Arch. Path., 51, 98. 